1. MD, FCPS (ENT)

Professor of ENT

Islamabad Medical and Dental

College, Islamabad.

2. MBBS, FCPS (ENT)

Consultant ENT

Ayub Medical Complex,

Abbottabad.

3. MBBS, FCPS (ENT)

Senior Registrar ENT

Hazrat Bari Sarkar Medical College

Islamabad.

4. MBBS, FCPS (ENT)

Senior Registrar ENT

Holy Family Hospital, Rawalpindi.

5. MBBS, FCPS (ENT)

Associate Professor ENT

Ayub Medical Complex,

Abbottabad.

6. MD, MCPS, FCPS (ENT)

Senior Registrar ENT

Benazir Bhutto Hospital, Rawalpindi.

Correspondence Address:

Dr. Syed Ali Naqi

Department of ENT

Islamabad Medical and Dental College

Islamabad.

greatsheragha@gmail.com

Article received on:

23/08/2019

Accepted for publication:

04/02/2020

\section{EVALUATION OF ELDERLY PATIENTS WITH HEARING IMPAIRMENT.}

\begin{abstract}
Syed Ali Naqi ${ }^{1}$, Syed Maisam Ali ${ }^{2}$, Arslan Akhtar ${ }^{3}$, Tabassum Aziz ${ }^{4}$, Tahira Sajid ${ }^{5}$, Akhtar Zaman ${ }^{6}$
ABSTRACT... Hearing is decreased in later age is due to aging and is normally seen in most of the elderly people all over the world. Objectives: To ascertain the degree of hearing in elders in relation to age, pattern and extent of hearing weakness in old age so that interventional strategies can be planned to improve their wellbeing. Study Design: Cross Sectional Study. Setting: ENT Outdoor Clinic of Akbar Niazi Teaching Hospital of Islamabad Medical and Dental College, Bhara Kahu, Islamabad. Period: December 2017 to October 2018. Material \& Methods: 200 patients were part of the study with age $>50$ years and no past history of drug therapy. Data was gathered by detailed clinical history, clinical examination and audiometric findings. Result: $57 \%$ patients were found with normal hearing and $43 \%$ had variable degree of hearing deterioration. Highest number of hearing weakness was found in 9th decade. Most of hearing deterioration was found in both the ears and that of sensorineural in type. Conclusion: Sensorineural type of hearing impairment is very frequently occurring problem seen in the latter part of life in our community. The frequency and severity of decreased hearing is directly proportional to age.
\end{abstract}

Key words: $\quad$ Age Related Hearing Loss, Elderly Patients.

Article Citation: Naqi SA, Ali SM, Akhtar A, Aziz T, Sajid T, Zaman A. Evaluation of elderly patients with hearing impairment. Professional Med J 2020; 27(10):21542158. DOI: 10.29309/TPMJ/2020.27.10.4071

\section{INTRODUCTION}

In this new era of $21^{\text {st }}$ century, there is a lot of increasing interest of medical researchers in the elderly population and age related changes in human body. The epidemiological data from the United Nations Population Division estimates that about 583 million population is affected by hearing deterioration in old age around the globe. This figure is estimated to get doubled by the mid of this century. ${ }^{1-2}$ The prevalence of hearing deterioration causing disability and effecting day to day activities for both adults and younger people is greatest in South Asia followed by Asia Pacific and Sub-Saharan Africa being on $3^{\text {rd }}$ place. $^{3}$ In later age there is every possibility for having other co-existing ailments because of generalized degenerative age related changes in the body which results in overall decrement in sensory, neural, and immunological activities. ${ }^{4}$

Severity of hearing deterioration may be divided into mild, moderate and severe to profound hearing loss, affecting either one or both the ears leading to social isolation because of social attitude taking hearing impairment as social stigma, friends loss resulting loneliness, difficulties in relationships which also causes loneliness, feeling of being embarrassed, all these resulting in depression, psychiatric disturbances. Relatively low earning jobs with restricted career choices (in young patients) and occupational stress. ${ }^{5}$ Age related hearing impairment can be defined as mid to late adult onset, progressively increasing sensorineural decreased hearing in both ears, while the other possible underlying causes of hearing loss have been excluded like hearing loss that is caused by primary factors including exposure to high and loud intensity sound, the intrinsic ear diseases (like; Otosclerosis, chronic discharging ear and Meniere's disease), hearing loss because of the underlying medical diseases causing loss as secondary effect (e.g. myxedema, hypertension, atherosclerosis, Paget's disease of bone, diabetics), injury to head and injury to ear 
and hearing loss due to use of medicines which are ototoxic. ${ }^{6}$

Age related hearing decrement is sensorineurol and termed as "presbyacusis" and it is this type of hearing loss which is most frequently causing chronic hearing loss in aged people. ${ }^{7}$ Microscopic studies of inner ear in cadaveric dissection of such ears was carried by Schuknecht \& colleagues in which they defined and explained six different categories of hiotopathological transformations in the cochlea of the ear 1. Loss of sensory type of hair cell 2. Degenerative loss of neurons of the cochlear nerve. 3. Atrophy of the cochlear vessels; stria vascularis 4. Mechanical Type 5. Alteration in the cochlear duct characteristics that are not evident on light microscopy but alter function at a submicroscopic level. 6. Mixed type- involving some contribution of the all the above five.$^{6-8}$ Pure Tone Audiometry is a simple diagnostic test tool which is performed by the audiologists and gives important information regarding the nature and intensity of hearing weakness for which further management plans can be exicuted. ${ }^{9}$

\section{MATERIAL \& METHODS}

This Cross Sectional study was conducted in ENT outdoor patient department of Akbar Niazi teaching hospital Bhara Kahu, Islamabad from December 2017 to October 2018.Total 200 patients with decrease hearing were registered and data collected from detailed history, clinical examination and Pure Tone Audiometry (PTA). PTA was performed by single audiologist using Inventis corso stati uniti 1/3 audiometer and data was analyzed with SPSS version20. The results were expressed in number and percentage. Degree of Hearing loss was measured.

\section{Selection of Cases}

\section{Inclusion Criteria}

Age $>50$ years, No past history of drug therapy which may cause sensorineural hearing loss.

\section{Exclusion Criteria}

People with previous history of aural discharge or history of trauma including noise trauma to the ear.

\section{RESULTS}

Among 200 patients 57\% (114) were found with normal hearing and $43 \%$ (86) had variable degree of hearing impairment. (Figure-1) The maximum occurrence of hearing impairment was detected in 9th decade (100\%) and (69\%) found in $8^{\text {th }}$ decades while lowest was $(30 \%)$ in 6 th decade. (Table-I) Most of the patients were found to be bilateral $67.44 \%$ (58) while $32.56 \%$ (28) had unilateral ear involvement. (Figure-2) Sensorineural type of hearing loss (69.76\%) which is significant number of patients in our study while (18.60\%) of conductive type and $(11.62 \%)$ had mixed type respectively. (TableII) $44.45 \%$ of hearing impaired patients of 6 th decade showed mild hearing loss while in the 7th decade maximum (50\%) had moderate to severe hearing loss whereas $31 \%$ patients of 8 th decade and $50 \%$ of 9 th decade had severe degree of hearing loss. (Table-III)

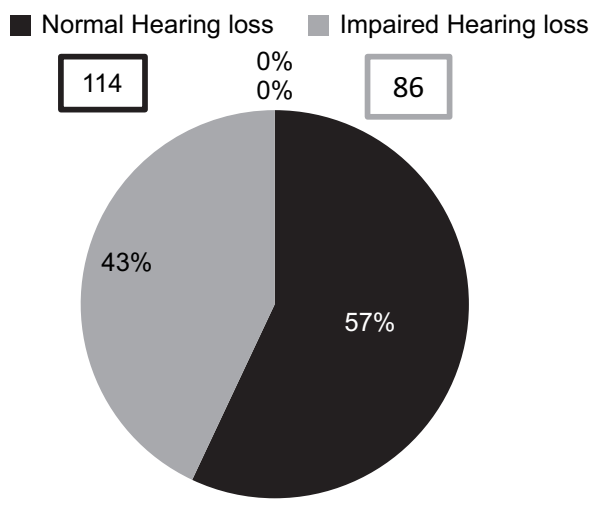

Figure-1. Distribution of hearing status $(n=200)$.

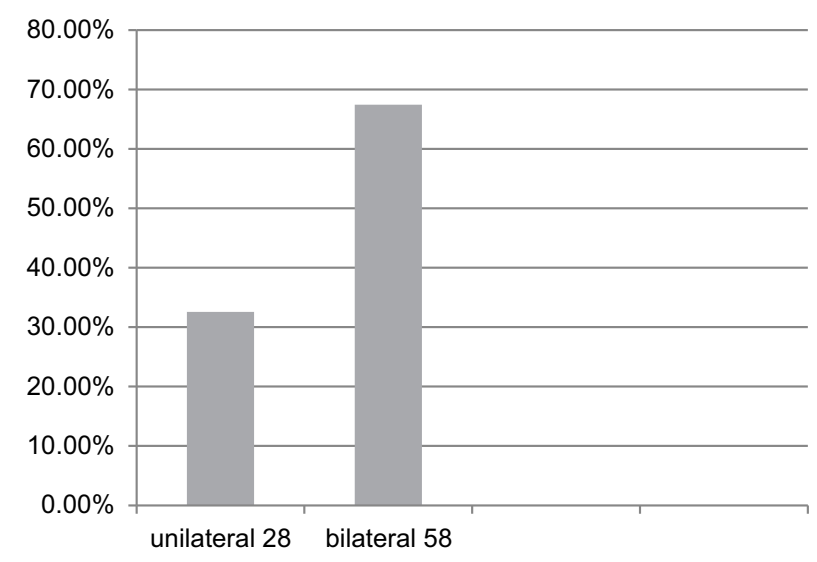

Figure-2. Involvement of unilateral/bilateral hearing loss population $(n=86)$. 


\begin{tabular}{|l|c|c|c|c|}
\hline Age Group (years) & Study Population & Normal & No. of Impairment & \%age \\
\hline $50-59$ & 120 & 84 & 36 & 30.0 \\
\hline $60-69$ & 30 & 18 & 12 & 40.0 \\
\hline $70-79$ & 38 & 12 & 26 & 68.42 \\
\hline$>80$ & 12 & 0 & 12 & 100.0 \\
\hline
\end{tabular}

Table-I. Frequency of hearing impairment in different age group $(n=200)$.

\begin{tabular}{|l|c|c|}
\hline \multicolumn{1}{|c|}{ Pattern } & Number of Impaired Patients & \%age \\
\hline Sensorineural & 60 & 69.76 \\
\hline Conductive & 16 & 18.60 \\
\hline Mixed & 10 & 11.62 \\
\hline
\end{tabular}

Table-II. Pattern of hearing impairment $(n=86)$.

\begin{tabular}{|l|c|c|c|c|c|c|}
\hline Age Group (years) & No of Hearing Loss & $\mathbf{2 6 - 4 0 d b}$ & $\mathbf{4 1 - 5 5 d b}$ & $\mathbf{5 6 - 7 0 d b}$ & $\mathbf{7 1 - 9 0 d b}$ & $>\mathbf{9 0 d b}$ \\
\hline $50-59$ & 36 & $16(44.45 \%)$ & $10(27.78 \%)$ & $6(16.66 \%)$ & $4(11.11 \%)$ & \\
\hline $60-69$ & 12 & $2(16.67 \%)$ & $4(33.33 \%)$ & $6(50 \%)$ & & \\
\hline $70-79$ & 26 & $6(23.08 \%)$ & $4(15.38 \%)$ & $6(23.08 \%)$ & $8(30.78 \%)$ & $2(7.69 \%)$ \\
\hline$>80$ & 12 & & $3(25 \%)$ & $3(25 \%)$ & $6(50 \%)$ & \\
\hline
\end{tabular}

Table-III. Relation of age with degree of hearing $(n=86)$.

\section{DISCUSSION}

Hearing impairment is one of the significant health problems of the community worldwide and especially prevalent in low economic societies of the developing countries like Pakistan. The prevalence of decrease hearing in adults is significantly higher in the middle and low income countries compare to well doing economic and developed countries of the world. ${ }^{2}$ Awareness regarding the pattern and severity of hearing loss can help the health professionals to make a proper diagnosis and provide better and timely treatment and rehabilitation facilities, but the pattern of hearing impairment may vary among different communities of the society, from one place to other, from one geographic region to other and from one hospital to other hospital. Such study helps in early disease detection and intervention, so helping in reducing disease morbidity and enhancing well-being and quality of life of the elder population.

Total of two hundred (200) patients above 50 years old, were studied after taking relevant thorough history, clinical examination and audiological investigation. In our study, minimum number of hearing impaired patients (30\%) was noted in the $6^{\text {th }}$ decade and gradually increasing the number of hearing impairment with increasing age and the maximum number $(100 \%)$ was found in the 9th decade. Bent $S$ et al. which showed results that the prevalence of hearing loss was maximum in age group of 6180 years followed by age group of 41-60 years which was $45.3 \% .^{10}$ We found $43 \%$ patients had impaired hearing in our study while Lee KYet al. also observed similar results of impaired hearing in Korean population which is comparable to our study ${ }^{11}$ Our study shows, $67.44 \%$ patients were found bilateral hearing impairment and $32.56 \%$ unilateral whereas Balatsouras DG et al. study consistent with the findings of our study. (Bilateral involvement was $65.85 \%$ and unilateral $34.15 \%) .{ }^{12}$ In present study (69.76\%) cases were found to have sensorineural hearing impairment, (18.60\%) conductive impairment and followed by $(11.62 \%)$ mixed type. Our results are very much similar with the findings of Yamasoba $T$ et al where sensorineural impairment $65.85 \%$ followed by conductive impairment $21.95 \%{ }^{13}$

We found gradual increase in the severity of hearing loss with increasing age in our study where $(44.45 \%)$ patients have been found to have mild degree $(26-40 \mathrm{db})$ hearing loss in the $6^{\text {th }}$ decade while $50 \%$ had moderate to severe degree (56- 
$70 \mathrm{db}$ ) in 7th decade and maximum percentage of severe degree (71-90db) seen in 8th and 9th decade. Ciorba $A$ et al have found increase in the severity of hearing loss with increasing age in Italian population, which supports our study. ${ }^{14}$

\section{CONCLUSION}

Our study concludes that age related sensorineural type is one of the major health issue and its prevalence and severity increases with increasing age.

With the development in health care delivery system and awareness programs can help in early diagnosis, screening programs oriented to old age, treatment and rehabilitation of hearing impairment for the improvement in the overall wellbeing and everyday patients' quality of life.

Copyright@ 04 Feb, 2020.

\section{REFERENCES}

1. Wilson BS, Tucci DL, Merson MH, O'Donoghue GM. Global hearing health care: New findings and perspectives. Lancet. 2017; 390:2503-15.

2. He P, Wen X, Hu X, Gong R, Luo Y, Guo C, Chen G, Zheng $X$. Hearing aid acquisition in Chinese older adults with hearing loss. Am J Public Health. 2018; 108(2):241-7.

3. Chadha S, Cieza A, Krug E. Global hearing health: Future directions. Bull World Health Organ. 2018; 96(3):146.

4. Mikkola TM, Polku H, Portegijs E, Rantakokko M, Rantanen T, Viljanen A. Self $\square$ Reported hearing status is associated with lower limb physical performance, perceived mobility, and activities of daily living in older community-dwelling men and women. J Am Geriatr Soc. 2015; 63(6):1164-9.
5. O'Donoghue GM, Tucci DL, Wilson BS. The mounting burden of hearing loss worldwide: Gearing up global collaboration. ENT Audiol News. 2017; 26:65-6.

6. Rahman MW, Ahasan Al, Debnath TK, Jamil AN, Barua $\mathrm{R}$, Amin MN. Study on hearing status of elderly patients attending a specialized ENT Hospital (SAHIC). Bangla J Otorhinolaryngol. 2015; 21 (2):80-4.

7. Fischer N, Weber B, Riechelmann H. Presbycusisage related hearing loss. Laryngo-rhino-otol. 2016; 95(7):497-510.

8. Luers JC, Hüttenbrink KB. Surgical anatomy and pathology of the middle ear. J Anat. 2016; 228(2):33853.

9. Rabbani SM, Chowdhury MA, Shumon AM, Yasmeen $\mathrm{N}$, Rashid M, Nuruzzaman M, Ahmed N. Pattern and causes of hearing loss among the patients attending in an ENT OPD. Anwer Khan Mod Med Coll J. 2014 3; $5(2): 9-13$.

10. Bent $S$, McShea L, Brennan S. The importance of hearing: A review of the literature on hearing loss for older people with learning disabilities. Brit J Learn Disabil. 2015; 43(4):277-84.

11. Lee KY. Pathophysiology of age-related hearing loss (peripheral and central). Korean J Audiol. 2013; 17(2):45.

12. Balatsouras DG, Felekis D, Panas M, Xenellis J, Koutsis G, Kladi A, Korres SG. Inner ear dysfunction in myotonic dystrophy type 1. Acta Neurol Scand 2013; 127(5):337-43.

13. Yamasoba T, Lin FR, Someya S, Kashio A, Sakamoto $\mathrm{T}$, Kondo K. Current concepts in age-related hearing loss: Epidemiology and mechanistic pathways. Hearing Res. 2013 1; 303:30-8.

14. Ciorba A, Bianchini C, Pelucchi S, Pastore A. The impact of hearing loss on the quality of life of elderly adults. Clin Interv Aging. 2012; 7:159. 


\begin{tabular}{|c|c|c|c|}
\hline \multicolumn{4}{|c|}{ AUTHORSHIP AND CONTRIBUTION DECLARATION } \\
\hline Sr. \# & Author(s) Full Name & Contribution to the paper & Author(s) Signature \\
\hline 1 & Syed Ali Naqi & Design, Data collection, & 52 \\
\hline 2 & Syed Maisam Ali & $\begin{array}{l}\text { Writing, drafting, Proof } \\
\text { reading. }\end{array}$ & \\
\hline 3 & Arslan Akhtar & $\begin{array}{l}\text { Writing, drafting, Proof } \\
\text { readiang. }\end{array}$ & \\
\hline 4 & Tabassum Aziz & $\begin{array}{l}\text { Writing, drafting, SPSS } \\
\text { statists. }\end{array}$ & \\
\hline 5 & Tahira Sajid & Design, drafting, writing, & \\
\hline 6 & Akhtar Zaman & Writing SPSS, Proof reading. & \\
\hline
\end{tabular}

